\title{
Scanning Electron Microscopy of Leaves of Southern Live Oak
}

\author{
Yadong Qi* and Ying Xiao** \\ *Urban Forestry Program, Southern University and A\&M College, Baton Rouge LA 70813 \\ **Department of Biology, Louisiana State University, Baton Rouge LA 70803
}

Southern live oak (Quercus virginiana Mill.) is a large evergreen broadleaf tree species that has significant landscape values in the U.S. This species is considered a virtual emblem of the Old South. Very little information is available regarding the leaf anatomy of the tree. This paper presents the scanning electron microscopy (SEM) of leaf gross morphology and anatomical features of live oak. The information will contribute to our better understanding of the physiology and morphology, tree growth and development of this species.

Sun-exposed leaves were collected from mature southern live oak trees on Southern University campus in the end of June. Leaves were prepared for scanning electron microscopy. They were dissected, fixed in FAA (Ethanol, Glacial Acetic Acid, and Formaldehyde), dehydrated in an ethanol series, and dried in carbon dioxide using Denton DCP-1 critical point drying apparatus. Leaves were mounted on stubs, coated with $25 \mathrm{~nm}$ gold palladium using a Hummer II Sputter Coater, and examined using a Cambridge S-260 scanning electron microscope.

The scanning electron micrographs of southern live oak leaves are illustrated in FIG. 1. The abaxial surfaces of the leaves are covered with a thick layer of trichome with multicellular peltate (shieldshaped) structure (FIG. 1a). A secretory function has been attributed to this type of leaf hairs [1]. A fully developed individual trichome shows as many as seventeen long narrow cells that are fused together for nearly half of their length. The surfaces of the trichome cells form a distinctive type of cuticle morphology, in which the outer surface is thrown into warty projections (FIG. 1b), indicating reinforced cell walls. This type of cuticle reinforcement was also reported in the leaf hairs of goosegrass (Galium aparine) [2]. The stomata are only presented on the abaxial surface and are generally covered up by the trichome. On the top of the guard cells around the stomatal aperture is cuticle serving as a primary protective layer in addition to the trichome layer (FIG. 1c). The adaxial leaf surface morphology is significantly different from the abaxial surface (FIG. 1d). The adaxial surfaces have no trichome at all and are smoothly covered by the cuticle and wax. The leaf transverse structure shows that the palisade tissue consists of three layers of compacted parenchyma cells (FIG. 1e). The thick trichome layer and closely packed palisade tissues are significant features of southern live oak leaves. The trichome layer functions as a mechanical barrier against biotic attack, an additional resistance to the diffusion of water vapor from leaf interior to the atmosphere, a reflector reducing the radiant energy absorbed by the leaf, and an absorber to help screen out harmful UV-B radiation from the sun. The closely packed palisade cells enhance photosynthesis efficiency by increasing photosynthetic sites and surface area of leaf interior. Thus, these leaf anatomical features provide southern live oak with specific eco-physiological advantages.

\section{Reference}

[1] J.H. Troughton and F.B. Sampson, Plants, John Wiley \& Sons Australasia Pty Ltd, 1973.

[2] B.S. Gunning and M.W.Steer, Plant Cell Biology Jones and Bartlett Publishers, 1996. 

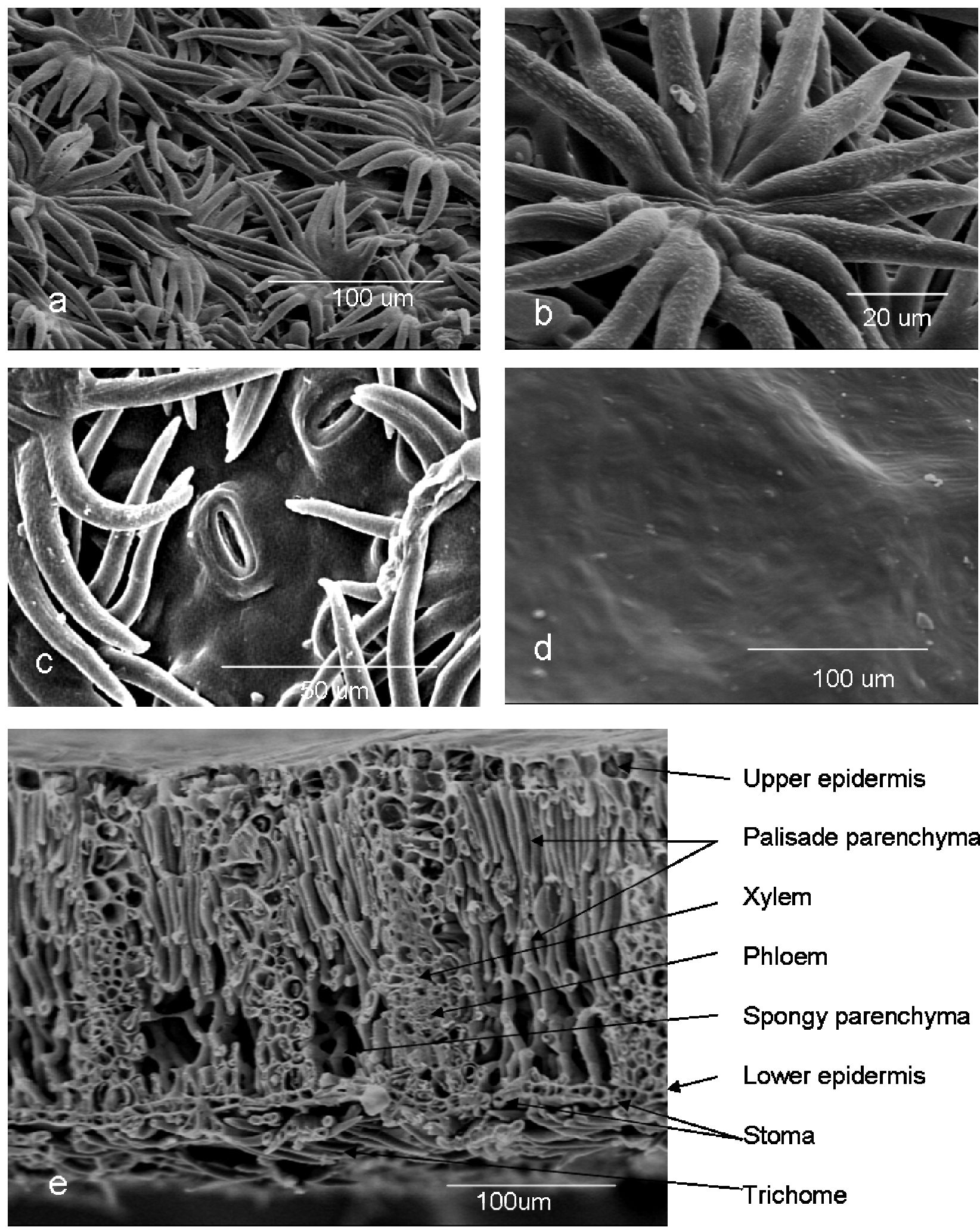

FIG. 1. Scanning electron micrographs of leaves of southern live oak (Quercus virginiana Mill.) a. Trichome of the abaxial leaf surface b. Enlargement of an individual leaf trichome
b. Stomata
c. View of the adaxial leaf surface
e. Leaf transverse view 